\title{
Speak of the Bubble - Constructing Comic Book Bubbles as Literary Devices in a Primary School Classroom
}

\author{
Lars Wallner \\ Department of Social and Welfare Studies \\ Linköping University
}

This is an Accepted Manuscript of an article published by Taylor \& Francis in the Journal of Graphic

Novels and Comics on 27 Dec 2016, available online:

http://www.tandfonline.com/http://dx.doi.org/10.1080/21504857.2016.1270221

When citing, please refer to the published article.

\begin{abstract}
This article investigates teachers' and pupils' use of speech and thought bubbles in a classroom literacy project involving comics. Through studying video data on naturally occurring classroom interaction whereby participants in Grade 3 (ages 9-10) talk about bubbles, the aim of this article is to increase knowledge of how bubbles are constructed as devices of literacy. The analysis focuses on the action-oriented aspects of discursive psychology: emphasis, word repetition, uptake, and the use of signs, symbols, and text in the comics. Results show how participants negotiate combinations of shapes, symbols, and text to construct common knowledge concerning bubbles. Furthermore, teachers use pupils' drawn bubbles, adding to them a variety of multimodal expressions, thereby illustrating how narrative focalization and character prosody are constructed in the reading of comics. The study of how bubbles are constructed contributes to a larger theme of studying classroom instruction using comics as resources for doing literacy.
\end{abstract}

Keywords: classroom interaction, comics, discursive psychology, literacy didactics, speech bubbles

\section{Introduction}

As materials for education, comics ${ }^{1}$ are a debated form of literacy (Bucher and Manning 2004, Chute 2008, Tilley 2012, Wertham 1954) ${ }^{2}$. However, they represent a medium that combines visual and textual aspects of literacy, and that in many ways is aimed specifically at children (Ripley 2012, Sutliff Sanders 2016), which makes them an interesting topic of study within the field of literacy didactics. Moreover, there are many different aspects of comics 
relevant to education that are worthy of study, from children's reading reception to vocabulary uptake. The present article focuses on one of the most distinct aspects of comics: speech and thought bubbles.

Speech and thought bubbles are fundamental to the comic book form, displaying the speaker's identity and emotional state, as well as the sequence of interaction (Cohn 2013a, Eisner 1985/2008, McCloud 1994, Yannicopoulou 2004). As a medium, comics combine text, image, gesture, facial expression, colour, and audio modes (Comer 2015), and bubbles afford the reader access to characters' voices - both their private inner thoughts and their public verbal expressions (Jacobs 2013, Lannon 2013). With the limited physical space that comics allow for expression, bubbles make use of pictorial representations and shapes in order to convey to the reader the emotional and audible form of messages (referred to here as prosody) (Eisner 1985/2008). For example, if a character expresses anger the thought bubble might be jagged, and if a character is shouting the font might be larger (cf. Cohn 2013a, Eisner 1985/2008, Yannicopoulou 2004). Of course, these conventions are not static or given, and may differ between different cultures or artists.

As this tends to be one of the first forms of (textual) literacy children encounter, they are aware of the conventions of bubbles, at least on a basic level, already at an early age (Yannicopoulou 2004). However, how are these conventions used in school practice? As the teacher in the present article, Anna, introduces a lesson on the topic of speech and thought bubbles, she asks "Why are they different?", thereby signifying that the different visual aspects used through bubbles as literary devices may be neither familiar nor obvious to all readers. If bubbles, or indeed comics in general, are brought into the classroom, what does this contribute to the pedagogical interaction around literacy?

\section{Multimodality in a bubble}

Multimodality designates "resources for representation", socially and culturally dependent semiotic resources of meaning making in communication (Kress 2010, 8). In face-to-face interaction, "participants encounter a steady stream of meaningful facial expressions, gestures, body postures, head movements, words, grammatical constructions, and prosodic contours" (Stivers and Sidnell 2005, 2), but this is also true of readers' encounters with comics (see, e.g. Cohn 2013b, Hammond 2009, Jacobs 2007).

Speech and thought bubbles are multimodal literary devices - resources for communication utilizing more than one modality (letters/words, font, colour, shape; see Kress (2010)) - that display the social dimensions of the emotional and epistemic stances of 
characters in a similar way to how the stance in question is demonstrated in everyday social interaction (see, e.g., Goodwin and Goodwin 2000, Goodwin, Cekaite, and Goodwin 2012, Jaffe 2009). These displays "are resources through which individuals can lay claims to particular identities and statutes as well as evaluate others' claims and statuses" (Jaffe 2009, 7), mimicking everyday social interaction in literary form.

Figure 1 shows two panels from a Donald Duck comic (Solstrand and Midthun 2013/2007). Here, for example, the author and illustrator have used capital letters in the speech bubbles of Magica De Spell and Donald Duck to indicate a louder volume of talk, or as with the two ducklings in the first panel, only bold-faced punctuation to signify surprise and shock (Eisner 1985/2008). The bubbles' shapes further indicate prosody: a jagged shape in the case of shouting in the first panel, and a cloudy, wobbly shape to indicate a shuddering coldness in the second. As such, it becomes clear that through changing the bubble frame, the font, or the size of the text, and through punctuation, the perceived audio quality of the talk changes, even though there is actually no sound at all (Eisner 1985/2008, Yannicopoulou 2004, also cf. McCloud 1994).

Figure 1. Bubbles (Solstrand and Midthun 2013/2007) (C) Disney, used with permission.
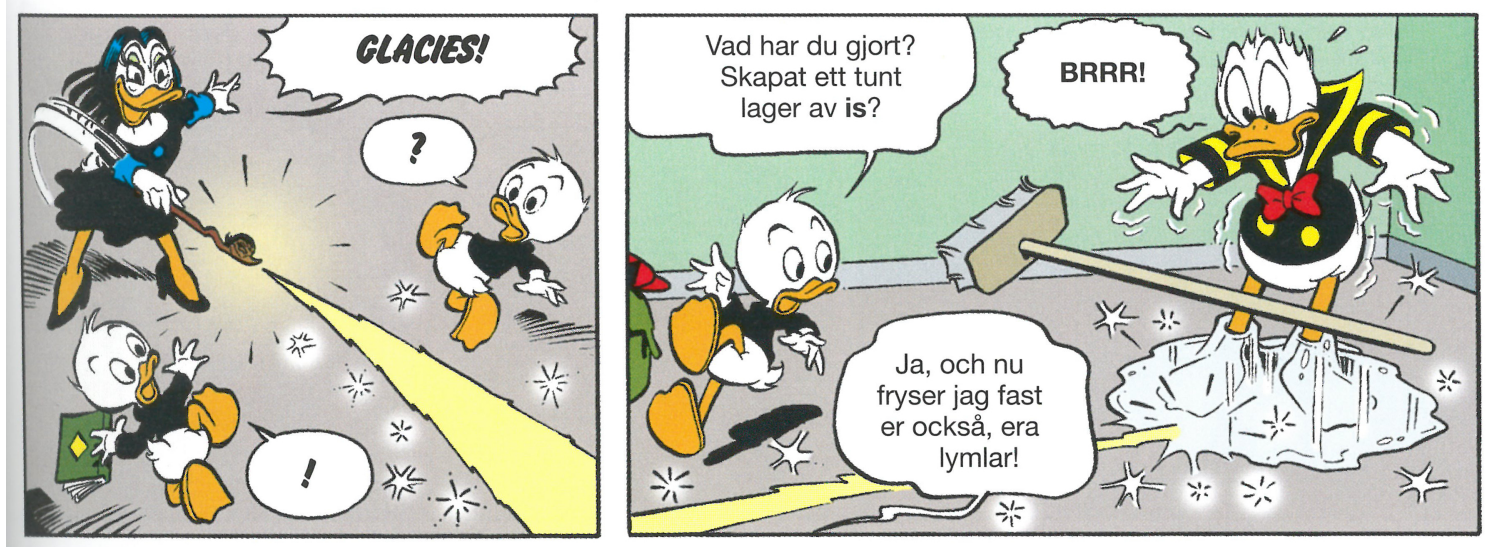

Furthermore, Figure 1 also demonstrates speakers interacting sequentially, responding to previous actions much in the same way as face-to-face interaction. In this case the speech bubbles are read from left to right and from top to bottom, as is the Western standard. Thus, the use of speech bubbles also displays speaker stance in relation to intersubjectivity, i.e. the way speakers understand each other (Du Bois 2007). Much like understanding social interaction (see Sacks, Schegloff, and Jefferson 1974), a reader of comics can understand speech bubbles sequentially: the action of the first speaker can be understood through the subsequent (re)action of the next speaker. As such, the surprise and shock displayed by Huey and Dewey reveal that Magica's actions are neither expected nor welcome (despite her own smiling demeanour). 
Bubbles also give the reader literary focalization, or narrative perspective (Culler 1997, Genette 1983), thereby enabling him or her to experience certain forms of dialogue and monologue that other characters may or may not be privy to. In Figure 2, another panel from Donald Duck (Barks 2013/1952) shows the two characters of Donald and Uncle Scrooge depicted as communicating through thought bubbles.

Figure 2. Adjacency awareness (Barks 2013/1952) C Disney, used with permission.

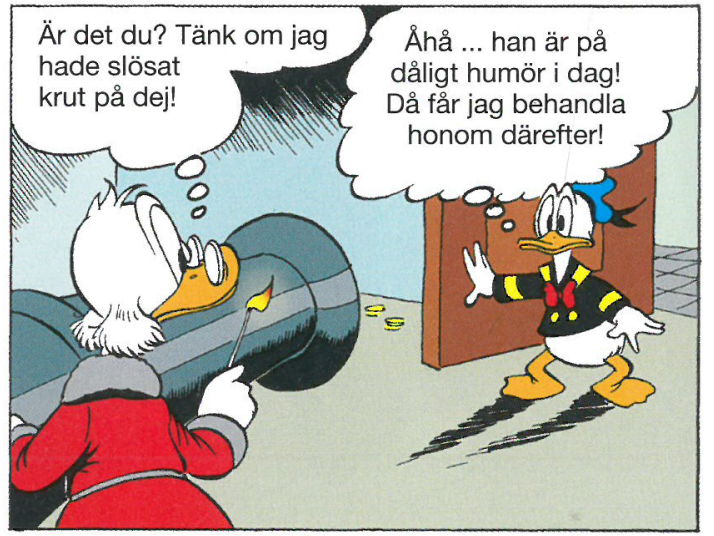

In this panel, the two thought bubbles signify to the reader that both characters are expressing something that the other does not hear. Cohn (2013a) describes this concept as root and adjacency awareness, in which characters (roots) within the comic have limited awareness of the bubble content produced by themselves and other characters (41). As an example of this, Figure 2 illustrates two roots (Donald and Scrooge), unaware of what the other person is thinking (i.e. lacking adjacency awareness). The reader, however, through a focalized omniscient narrative perspective (what Genette (1983) calls zero perspective), is given access to the thoughts of both characters, showing both Scrooge's economic perspective ("Is it you? Imagine if I'd wasted gun powder on you!”), and how Donald views Scrooge (“Oh ... he's in a bad mood today! I'll have to treat him accordingly!"), which guides Donald's subsequent actions throughout the comic.

These are examples of literacy aspects that may seem obvious to adult readers, especially those with experience of comics. However, in educational interaction, teachers have the difficult task of trying to assess and relate to a framework of cultural reference that needs to be contextually and socially constructed in order to make common sense (Edwards and Furlong 1978, Edwards and Mercer 1987). Teachers cannot assume that all participants share the same frame of reference. One contributing factor to relate to this common sense is language, the use of which positions "the learner as an active participant in the making of meaning" (Barnes 1976, 31). When using comics in the primary school classroom, speech and thought bubbles are quintessential devices of visual literacy that need to be 'properly' 
understood (cf. Gillenwater 2014) in order for the group to have a common reference frame. By adopting a view of comics as being a literary framework in which visual aspects, such as panelling (Cohn 2013b), gutter (Author (submitted)), and bubbles (Cohn 2013a), can be attributed grammatical and narrative functions, what can teachers and pupils do with these literary devices?

As comics studies comprise a small, but growing, field of research, especially in the Nordic countries (Strömberg 2016), there is a gap in the knowledge of how comics are used in Swedish classroom practice. Furthermore, previous research on comics as materials for education (e.g. Bitz 2004, 2008, Low 2012, Pantaleo 2011, 2012, 2013, Yannicopoulou 2004) focuses on performing educational experiments, conducting singular case studies, or discussing theoretical approaches to the use of comics.

In their study of 42 college students taking part in composition classes, Dickinson and Werner (2015) suggest that the multimodality of comics allows for the format in general to be used in educational contexts as a means of expanding thinking around literacy. Furthermore, in a study of preschoolers, Yannicopoulou (2004) shows that children are aware of the visual communicative conventions of comics (the use of bubble frames and different text sizes) even before they are textually literate. However, since Yannicopoulou's study focused on the experimental testing of children's knowledge of bubbles, and as an increasing number of other literary forms have adopted the use of bubbles as a form of communication (Yannicopoulou 2004), it is interesting to investigate how teachers and pupils explore the use of these multimodal literary devices in naturally occurring (Potter 2010) classroom interaction - how teachers teach these devices, and what is done in the ongoing talk.

Resources for representation - whether in interaction between a text and a person or between two persons - are continually remade both in context and in translation between cultures (Kress 2010, Potter 1996), and, as such, we cannot (and should not) make grand generalizations about communication (The New London Group 1996). Instead, the present article presents a microanalysis of practical examples of participants' use of comics as resources for literacy. Studying this in situ practice through careful and repeated analysis of video observations allows the analyst to see patterns of interaction in which different resources are drawn upon, and how these influence the literacy context of the ongoing lesson. Furthermore, providing detailed transcriptions of talk and embodied action enables the reader to evaluate the analysis, democratizing the process and encouraging discussion. As such, by gathering multiple studies of these kinds, we can collect larger pools of analysis, where broader patterns of interaction can emerge (Potter 2003). 


\section{Aim of the study}

The aim of this study is to increase knowledge of how bubbles are constructed as devices of literacy in classroom practice. This adds to the existing body of knowledge by instead exploring how primary school participants, teachers and pupils in naturally occurring classroom practices (Potter 2010), construct comic book bubbles as aspects of interaction. Through studying a situation not designed by the researcher, this research presents a new perspective on how teachers and pupils engage with the material, what interactive repertoires are displayed, and how participants perform actions in a social context (cf. Potter 1996, Wiggins and Potter 2007). As such, a valuable addition can be made to the field of literacy didactics, which can benefit further research as well as inspire practicing teachers.

\section{Participants, data, and transcription}

The data were recorded as part of a larger study of comics in education, involving six teachers and 77 pupils in Grades 3 (9 years old) and 8 (14 years old) in Swedish compulsory school, totalling approximately 36 hours, or 15 lessons. All names have been changed for reasons of anonymity, and the pupils' parents have given written consent to their child's participation in the study.

The participants in the present article are all teachers and pupils in one of the classes in Grade 3, who had decided to use comics as a means of learning Swedish. Over a period of three weeks, the class worked on a project involving reading Donald Duck comic book albums, coupled with different types of exercises. The subject is Swedish, and the curriculum includes different aspects of reading and writing (Swedish National Agency for Education 2011), although with nothing specifically related to comics. Four video cameras were used to capture participant talk, gestures, and gazes.

One difficulty posed by working with video data concerns the ability to represent it to the reader. As the construction of bubbles is the phenomenon being studied, a form of comic book transcription was considered appropriate for the purpose of displaying participant sequences of talk, tone of voice, prosody, and embodied actions. The data have been analysed using the original videos, supported by textual transcriptions (Jefferson 2004). In order to best represent the visual and aural aspects of the data, frame grabs from the video, in combination with textual transcripts ${ }^{3}$ and drawn bubbles (based on Thompson 2008), have been assembled as graphic transcripts (Laurier 2014) ${ }^{4}$. The panels have been numbered for the sake of reference. A visual transcription key is provided as Appendix 1. The faces, hands and hair of 
all participants have been traced and whitened merely to preserve anonymity; this does not represent skin colour, and is not meant to highlight visual features in any way.

\section{Studying literary practice as social interaction}

With a focus on three primary aspects - action orientation, situation and construction - the field of discursive psychology studies text and talk as inherent social practices (Potter and Edwards 1999, Potter 2000, Potter and Edwards 2003). Based on this, the present article treats discourse as being socially constructed and re-constructed by individuals and groups in a cultural and social context with the tools and information at the participants' disposal. Thus, through the analysis of video and audio recordings of classroom interaction, the focus here is on the interactional resources, sequential practices, and discourses utilized by these participants in the uptake of, and orientation to, prior positioning in conversations or texts (Mehan 1979, Sacks, Schegloff, and Jefferson 1974). For examples of research combining discursive psychology and naturally occurring literacy practices, see Eriksson Barajas (2002), Allington and Swann (2009), and Allington (2012).

Looking at verbal and non-verbal aspects of social interaction (such as tone of voice, intonation, repetition of phrases and words, upgrades) and participants' embodied actions (such as gestures, posture, and facial expressions), groups of interactional phenomena have been analysed systematically and repeatedly using a participant-oriented perspective, asking how a certain action is performed (Potter 2010).

In this way, talk about speech and thought bubbles has been found in the recorded material. This phenomenon occurs spontaneously (e.g. pupils reading bubbles in comics to each other, or teachers and pupils commenting on bubbles during drawing sessions) as well as formally (e.g. a lesson or part of a lesson focusing on bubble use, as will be shown below) throughout the material in Grade 3. In Grade 8, there are sequences of reading in which the interpretation of bubble meaning becomes relevant (similar to what is shown in Excerpt 4, below), but the formal negotiations and discussions seem to be non-existent. This could be because of the difference in school topics, with Grade 3 having Swedish language studies as a topic (including reading and composing texts) and Grade 8 studying social science and focusing more on the content of the comics.

For the present article, four excerpts from the material are analysed and presented. The first three are taken from the same 40-minute lesson and the final one from a later lesson, all with the same group of 14 pupils and three teachers. The first three excerpts were chosen as they most clearly demonstrated different aspects of the investigated phenomenon, with 
teachers and pupils taking a formal, meta-perspective in their instructional talk about bubbles as a device for doing literacy. The final excerpt shows a different perspective on how this literary device is constructed in the natural reading practice between teacher and pupil.

\section{Establishing literary focalization through speech and thought bubbles}

The following three excerpts are taken from the first lesson this class had in a Swedish language project with comics as its basis. The teacher, Anna, initiates the topic by asking if the class knows what speech bubbles are. After a show of hands, the following takes place:

\section{Excerpt 1}

"Diana's cloud". SK0304_GMG. Participants: Anna (teacher), Diana (pupil)

Figure 3. Excerpt 1
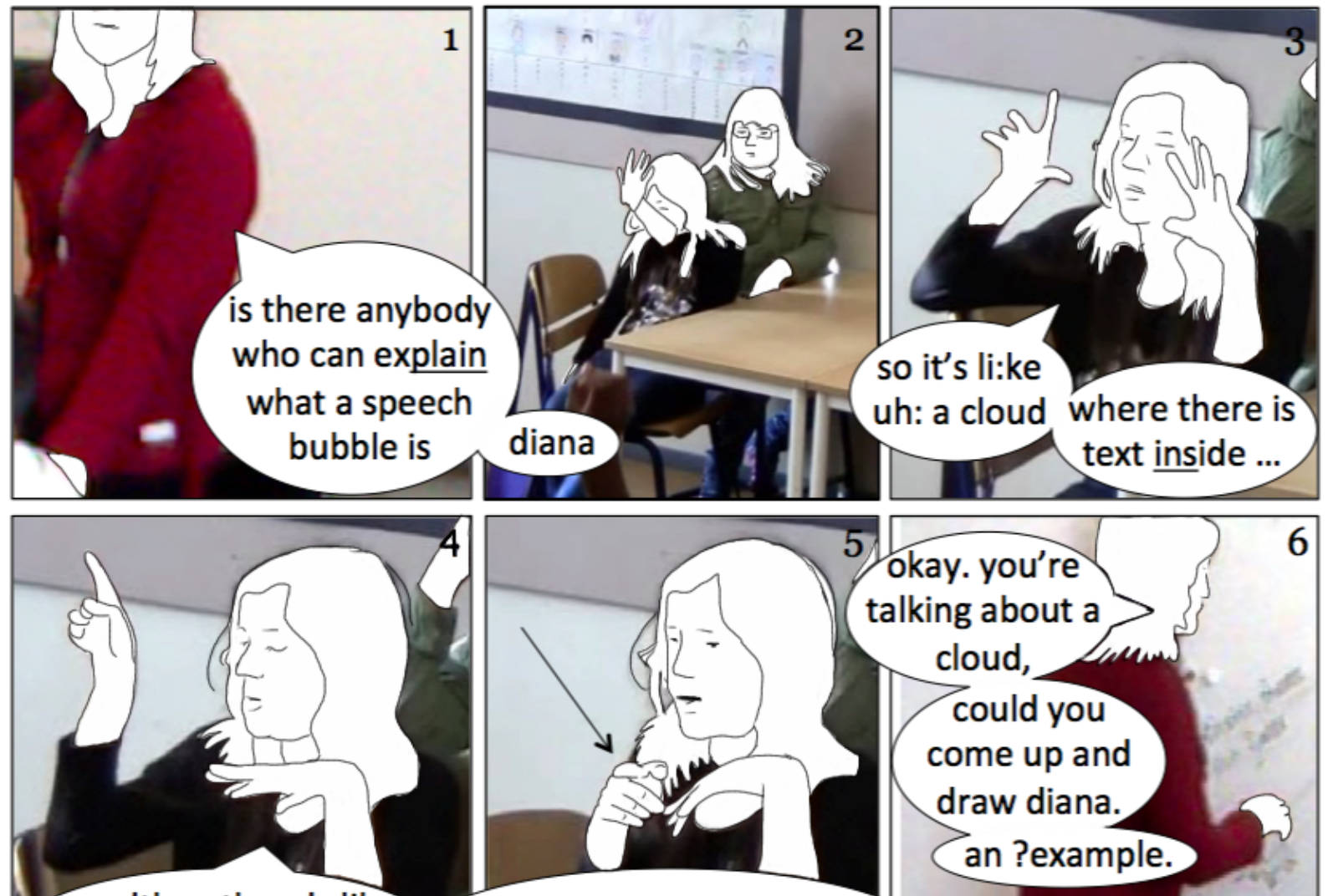

okay. you're

talking about a

... an'then there's like o:n that person so that they one of those lines there are the one who's talking

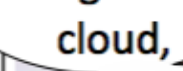
could you come up and draw diana. Can ?example.

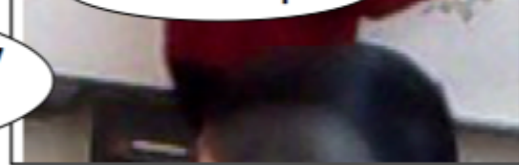

In Excerpt 1, Anna (the teacher, in Panel 1) asks for someone to explain to the group "what a speech bubble is" (1). In establishing this, she demonstrates a pedagogical view of the pupils as bearers of knowledge. However, through her question, Anna also establishes this knowledge of comics conventions as a matter of communal interest (Bruner 1990, Edwards and Mercer 1987) and at the same time establishes the literary device of "speech bubble" as something that requires explanation and analysis. This allows the teacher to elevate an 
individual understanding of the terminology at play to a common understanding (Bruner 1990, Edwards and Mercer 1987); i.e. by making this request, Anna establishes the device as something that merits teaching.

Diana (the pupil closest to the camera in Panel 2) then explains that a speech bubble is "li:ke uh: a cloud (pause) where there is text inside (pause) an'then there's like one of those lines there (pause) o:n that person so that they are the one who's talking" (3-5). She also gestures in front of her, illustrating the cloud (3) and the line (4-5). This describes the visual essence of a speech bubble: a carrier, a surface with text, somehow connected - through a tail - to a speaker, or root (Cohn 2013a, see Figure 4). As it is, one could argue that Diana's explanation of the bubble is adequate-for-all-practical-purposes (Garfinkel 1967/1984), associated with making the purpose of a speech bubble understandable to the other participants.

Figure 4. Diana gesturing, inspired by Cohn (2013a).

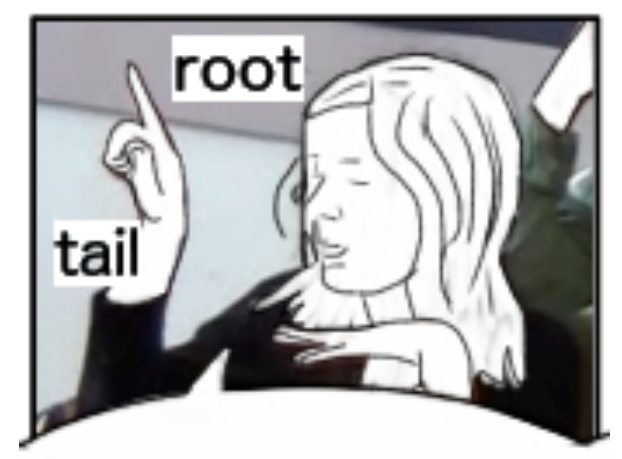

carrier

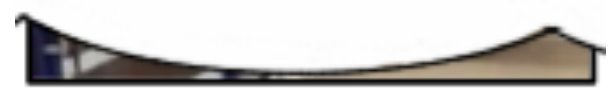

Diana's explanation draws some comparisons to other common objects (cloud, text, line) that other participants can be assumed to be familiar with. She couples this verbal talk with physical gestures, illustrating the visual aspects she is describing. This shows that even though the objects referred to may in themselves be known, it is necessary to demonstrate their physical positioning in relation to each other, and to the speaker. The visuals of root, tail, and carrier are of major significance for comic book communication, so when defining what a speech bubble is it becomes important to distinguish these parts as well (Cohn 2013a).

Thus, Diana's explanation demonstrates a complementary visual and verbal explanation of a speech bubble, which is primarily a visual object rather than a verbal one. In pedagogical interactions, this construction of a visual/verbal discourse of learning these devices could facilitate communal understanding (Edwards and Mercer 1987, 156-157). As a response to 
Diana's visual-verbal description Anna asks her to come up to the board (6) and draw her speech bubble (Figure 5), requesting that a further visual aspect be added to this discourse of communal learning, this time materialized on the board.

Figure 5. Diana's speech bubble drawn on the whiteboard.

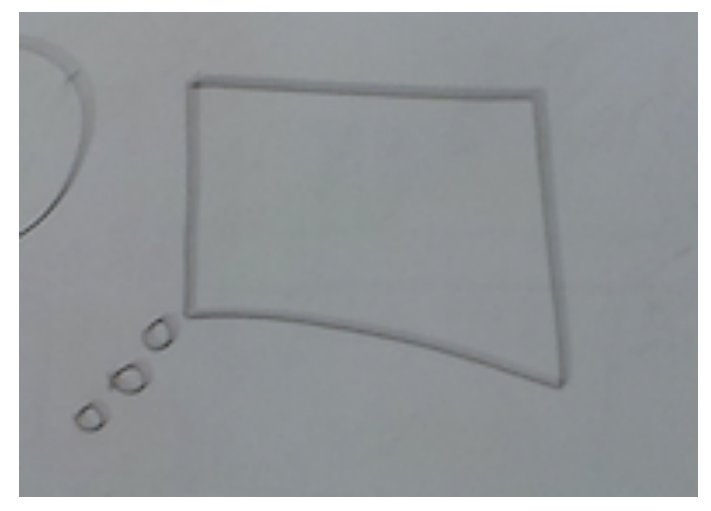

Diana's drawing is quite different from her verbal explanation, but the components are similar - a framed 'bubble', which is connected to an imagined speaker in some way. The fact that she draws something different from her verbal explanation illustrates the varying forms of bubbles, which will be explored further below. When Anna continues by asking more pupils to add to this example, stars, circles, rectangles and other shapes are drawn on the board (Figure 6).

Figure 6: The group's speech and thought bubbles drawn on the whiteboard.

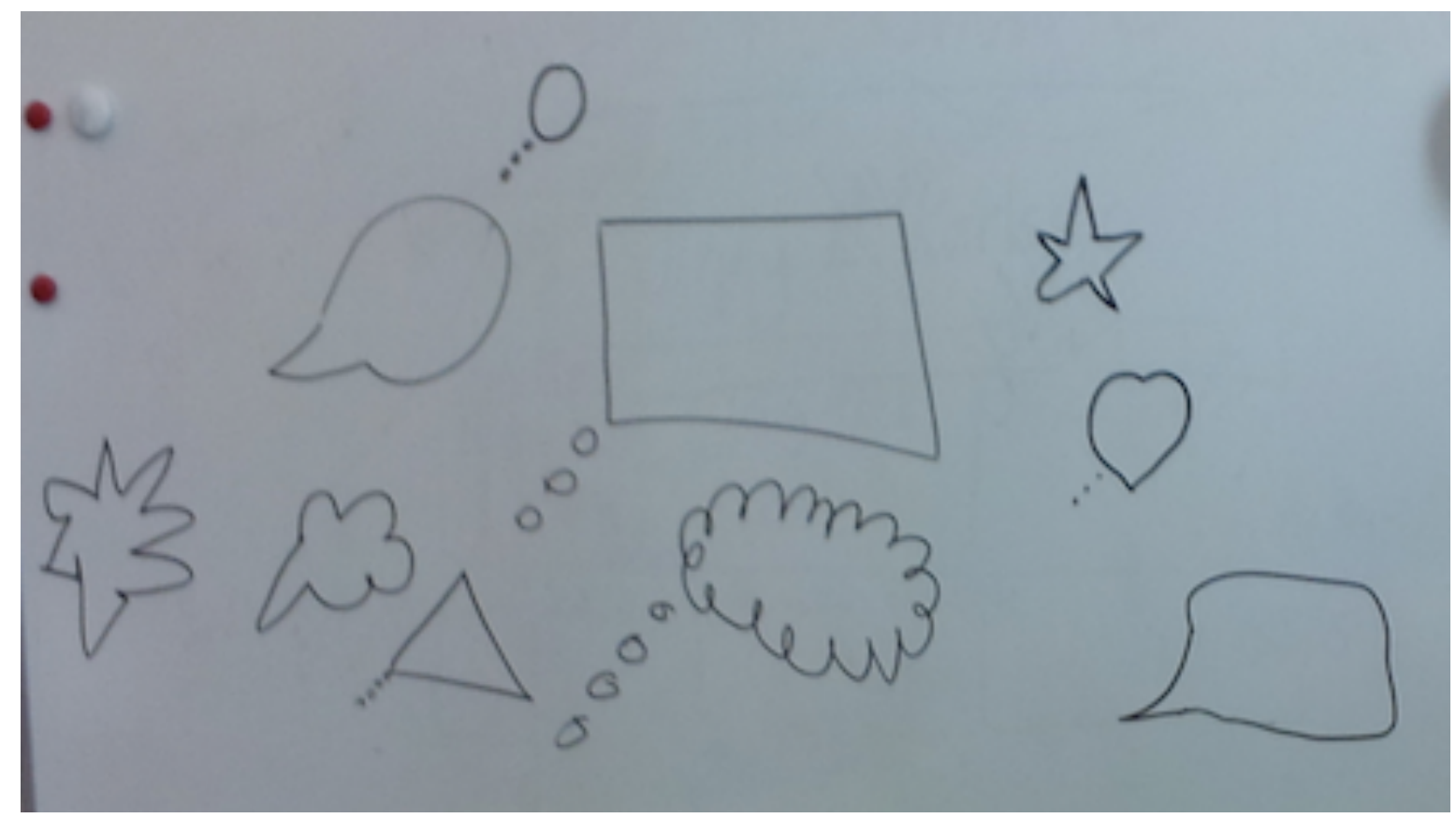

In this way, a group of speech bubbles is collected on the whiteboard, and at the same time a demonstrated outline of the shared understanding of bubbles is developed through this process. Each bubble is a contribution of knowledge from one child, and together they make 
up a sort of common vocabulary, contextual terms of reference needed to better understand the topic (Edwards and Mercer 1987, 80). Simply having the picture of a bubble on the board does not mean each individual in the room now shares the knowledge of how to make sense of that bubble. However, the materialized group of speech bubbles constitutes a base from which knowledge of function and use is developed throughout the lesson, as will be shown in Excerpt 2.

\section{Excerpt 2}

"Thought bubble". SK0304_GMG. Participants: Anna (teacher), Josefin (pupil).

Figure 7. Excerpt 2, 1-2

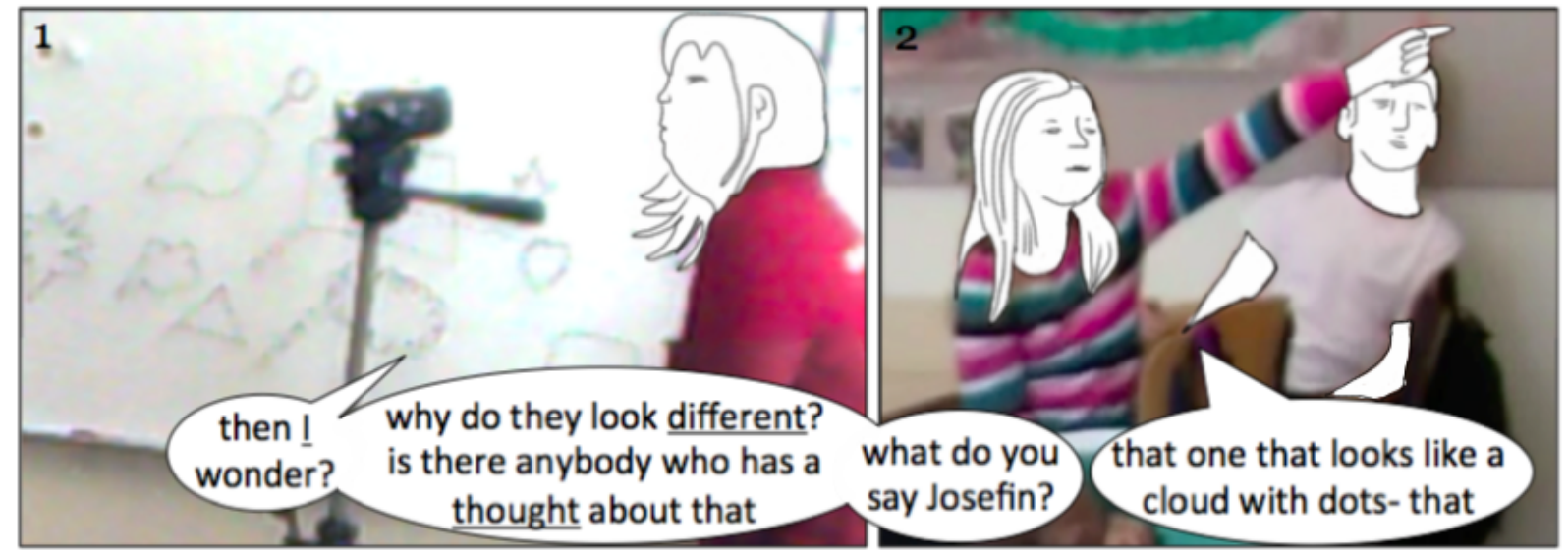

Figure 8. Excerpt 2, 3-5

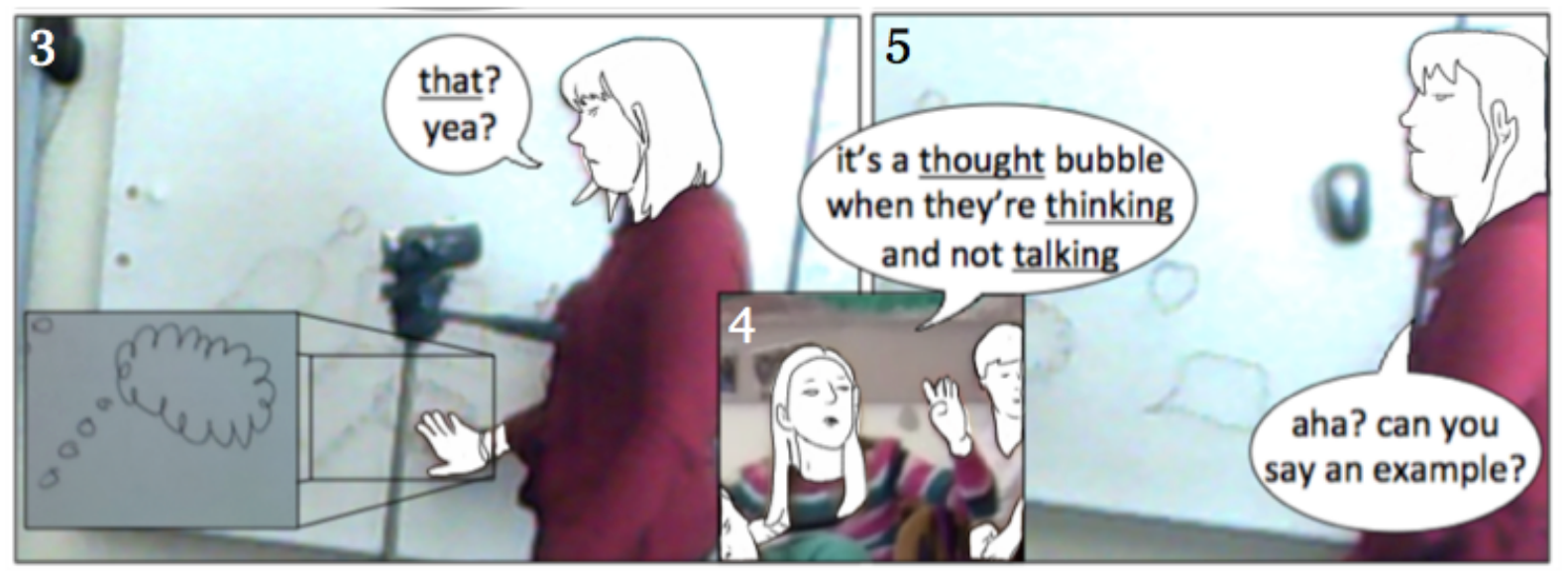

At this point, the teacher's question in Panel 1 "why [---] they look different", performs the action of moving the focus of the lesson to the literary function of the bubbles (what do the bubbles do?), rather than how they are described (what does a bubble look like?). Josefin (the pupil to the left in Panel 2) explains that the bubble that "looks like a cloud with dots" (2) differs from the previous speech bubble (Excerpt 1), as this is "a thought bubble when they're thinking and not talking" (4). Thus, she identifies, and separates, two narrative perspectives, or focalizations: inner thought and public talk - the point-of-view of the narration (Culler 1997, 88, Genette 1983, 189). Focalization allows the participants to reflect on the narrative 
perspective, which narrator is being used, and how this affects the reading experience (cf. Comer 2015). Here, Josefin offers a construction of the bubble in which the reader is made aware of the mental expressions of a character, even though the other characters are not aware of this.

This construction is similar to Cohn's (2013a) root and adjacency awareness (above), demonstrating to the reader which character is in narrative focus (from whose perspective we are experiencing the story), or if the narration is omniscient (as in Figure 2, above). This construction of how the shape of the bubble is to be understood guides these pupils in their reading of bubbles - how to interpret different bubbles as means of creating a focalization of narrative.

In Excerpts 1 and 2, the participants describe bubbles in two different ways: aesthetically (what the bubble looks like) and functionally (what the bubble does). Both descriptions could operate as signifiers, allowing a participant to single out a certain bubble from the general group. Both descriptions also require a common understanding either of the bubbles as literary devices, or of conventional shapes. In Excerpt 2, both descriptions are utilized: the aesthetic description is seemingly used to separate one bubble from the group ("the one that looks like a cloud"), and then its function is defined - conveying thought. This, of course, makes sense in the classroom setting: Josefin's fellow pupils are more likely to be familiar with, and able to single out, the shape of a cloud amongst a group of bubbles, than that bubble's literary function.

In the following, we will take a closer look at how the teacher utilizes these aesthetic qualities, drawing upon different interactional modalities in her construction of textual messages in comics literacy.

\section{Doing comic book prosody through multimodal actions}

It has been shown how the group constructs different bubble shapes as literary devices for narrative focalization. This is done through an aesthetic differentiation between bubbles, as well as talk constructing how root, tail and carrier are functionally related to each other, and their role in the narrative. However, when pupils are asked to give suggestions for what could be written in the different bubbles (Figure 6), the teacher adds another layer to the suggested message.

\section{Excerpt 3}

"Bang”. SK0304_GMG. Participants: Anna (teacher), Sarah (pupil).

Figure 9. Excerpt 3, 1-6 


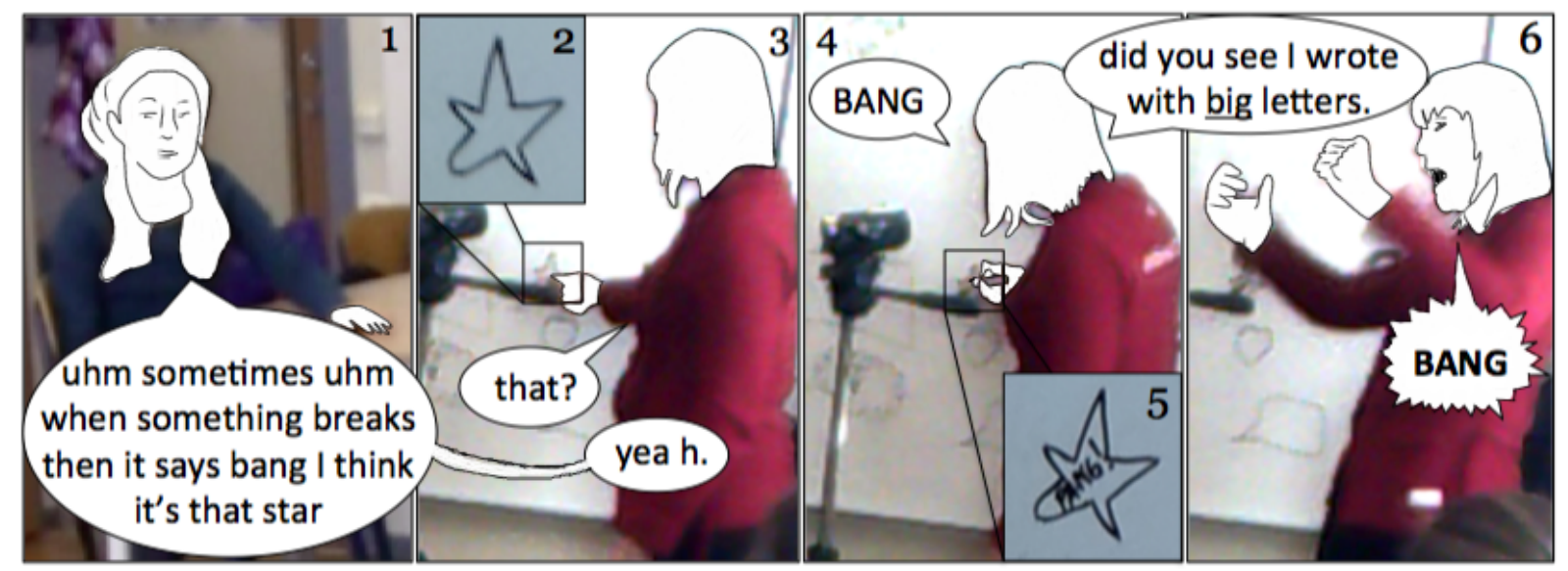

Figure 10. Excerpt 3, 7-9

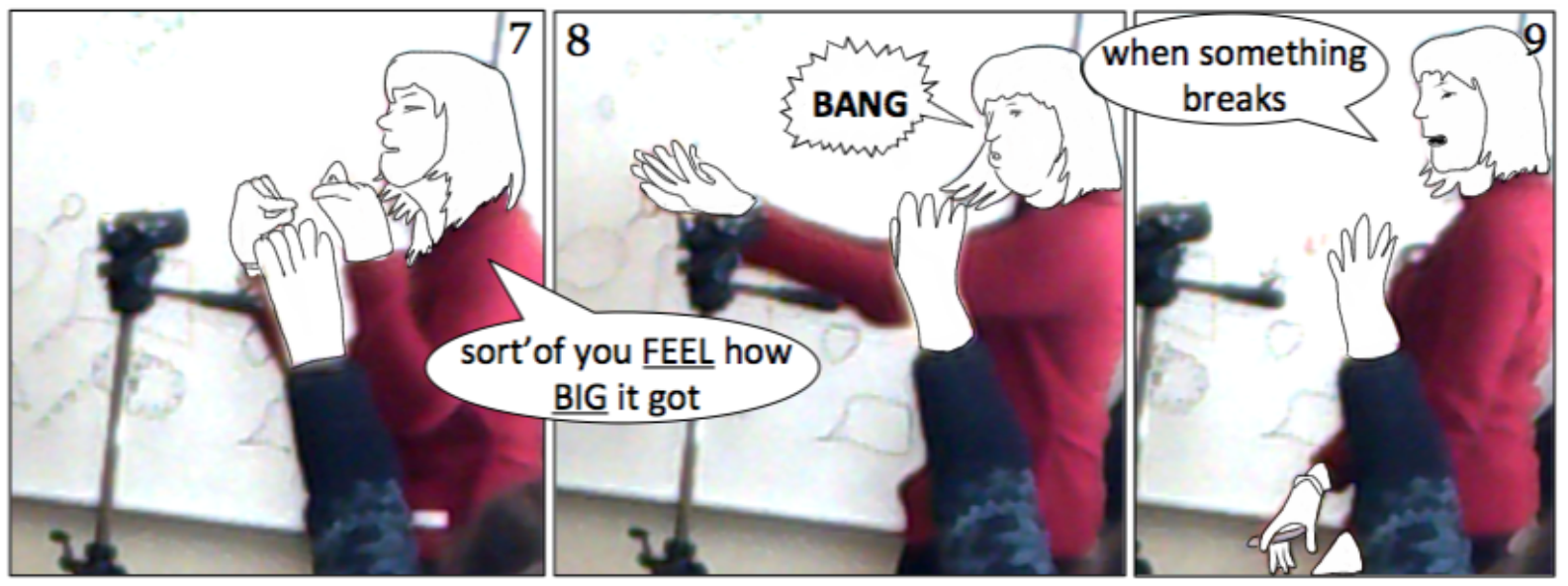

In Excerpt 3, Sarah (the pupil in Panel 1) suggests that the star (2), being one of the bubbles, represents something breaking and saying "bang" (1). Anna, in Panel 3, points to the bubble (3), and writes the word "BANG!" inside it in capital letters, followed by an exclamation mark (4-5).

Again, we find a common shape presumably familiar to most pupils, namely a star. The star shape could be said to pictorially represent an explosion, something commonly done in comics (although not used exclusively for this purpose; see Cohn (2007)), and so the shape gives visual cues as to how the textual message should be read - the shape of the star indicates that this is not something expressed by a character, but rather a sound effect. Sarah (perhaps unknowingly) orients to this not only when identifying this bubble as a "star", constructing it as an onomatopoetic sound effect (Lannon 2013), or action star (Cohn 2012), but also through her use of the impersonal pronoun - "it says bang” (1, author's emphasis), unlike Josefin and Diana in the previous excerpts who use the personal "they".

When Anna has written in the bubble on the board, she loudly repeats the word "BANG" (4-6), and draws attention to the fact that she has written it in capital letters, often used in comics to indicate loudness through the use of lettering (Jacobs 2013, Thompson 2008, 
Yannicopoulou 2004). In the proceeding turns (6-9), the volume of her voice shifts between loud and normal, loudly emphasizing key words such as "feel", "big" and "bang" to convey the sensation of an explosion, which also emphasizes these sounds and feelings as being discursively important for the pupils to pick up on (cf. Edwards and Mercer 1987). She also couples this talk with gestures portraying an explosion, visually, aurally and verbally demonstrating the prosody of the utterance.

Dickinson and Werner (2015) show how the use of comics allowed their students to ask "What kind of voice does this speaker have?" (55). In their article, the authors discuss character authority and the difference in power between famous scholarly characters and student characters. However, this question is also more literally significant, with respect to what prosody can be read from the visuals of character and textual message, and what difference this makes for the experience of readers. In Excerpt 3, Anna has asked the same question in relation to particular speech bubbles, also using punctuation as a compositional means of producing the sound. The inferred meaning and subtext Anna adds through her use of gestures, material aspects of the whiteboard, and sound shows that some of the information is displayed in writing, while some is inferred from characters' facial expressions (see Excerpt 4 , below), or otherwise visually displayed through symbols or choice of font, font size, and bubble shape, rather than through the written text (Eisner 1985/2008).

The way the teacher uses her voice and body in different combinations to display narrative tone mirrors the way the bubbles display characters' facial expressions, but also the effect that frame, colour, and textual art (in this case capital letters) have on written text. The action of taking on the character role displays a demonstration of emotion and sensation, which allows the pupils to both visualize the root and hear the different expressions represented by the speech bubbles. The children are taught that through the combination of certain text, framing, and context, a phrase or word has a certain sound quality which demonstrates an emotional, or affective, stance (Goodwin and Goodwin 2000, Goodwin, Cekaite, and Goodwin 2012, Jaffe 2009) of a comic book character. Similarly, Terry Thompson (2008) suggests teaching primary school children different forms of punctuation, through the use of graphica, or comics. In his classroom, children are encouraged to envision the sound of the sentence, how it should be read aloud, emphasizing the use of different visual cues afforded by the bubbles. As Lannon (2013) points out in an article on the function of words in comics, the reader's experience of an explosion can be very different depending on what word is used to signify it. The words 'bang', 'boom', 'pop', 'poof', and 'ka-blam' could all be used to signify explosions, but the way the reader perceives what kind of explosion it is would presumably be 
different. This way, the teacher in the present article puts into practice the use of different visual cues to construct different prosodic meanings from the same word.

\section{Constructing prosody in comic book reading}

In the final excerpt, two weeks have passed since the lesson on speech and thought bubbles depicted above. Moving on from the previous whole-class talk in Excerpts 1-3, in which participants engaged in discussions on how bubbles could be constructed, this excerpt shows a practical act of reading a comic book in which the participants construct visual information (e.g. bubbles and facial expressions) and the textual information both within and outside the bubbles (letters/words and punctuation) into a narrative. Here, Anna (the teacher, on the right) and John (the pupil, on the left) are reading a comic book together. This particular comic ${ }^{5}$ features the Beagle Boys trying to gain access to a building (3), only to fall through a trapdoor onto a platform, surrounded by crocodiles (2).

\section{Excerpt 4}

"Crocodiles". SK0319LAS. Participants: Anna (teacher), John (pupil).

Figure 11. Excerpt 4, 1-4

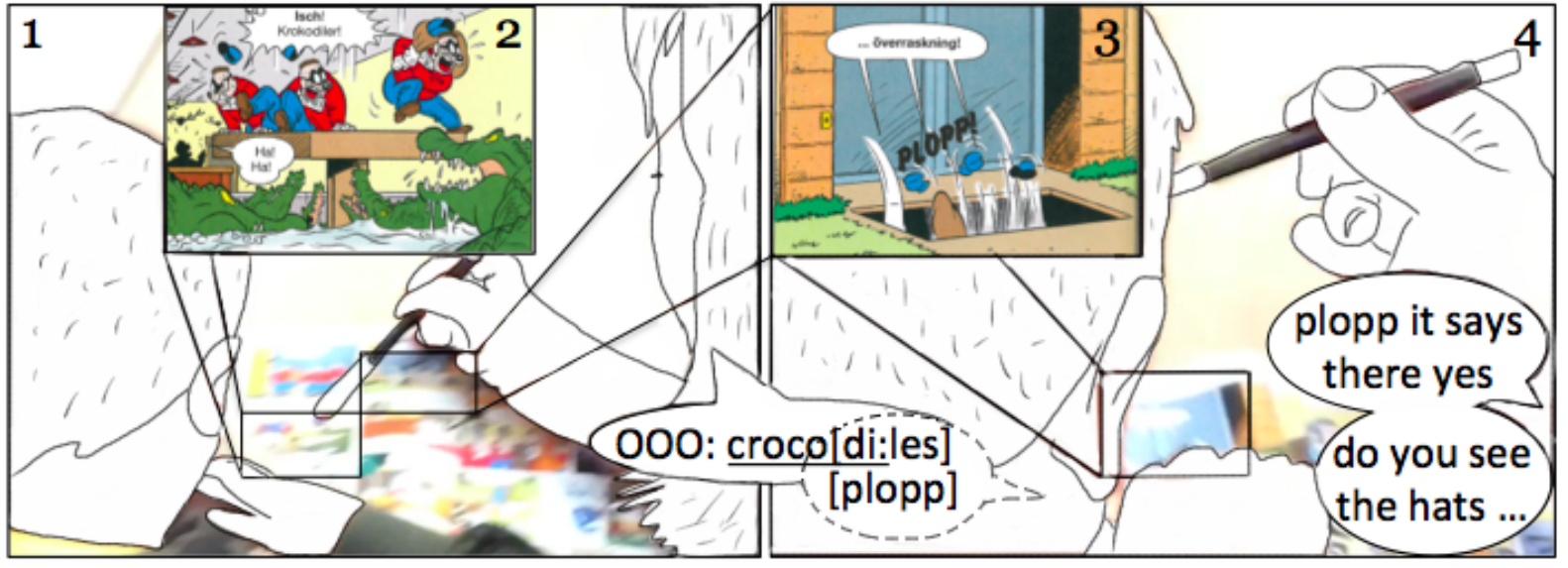

Figure 12. Excerpt 4, 5-6
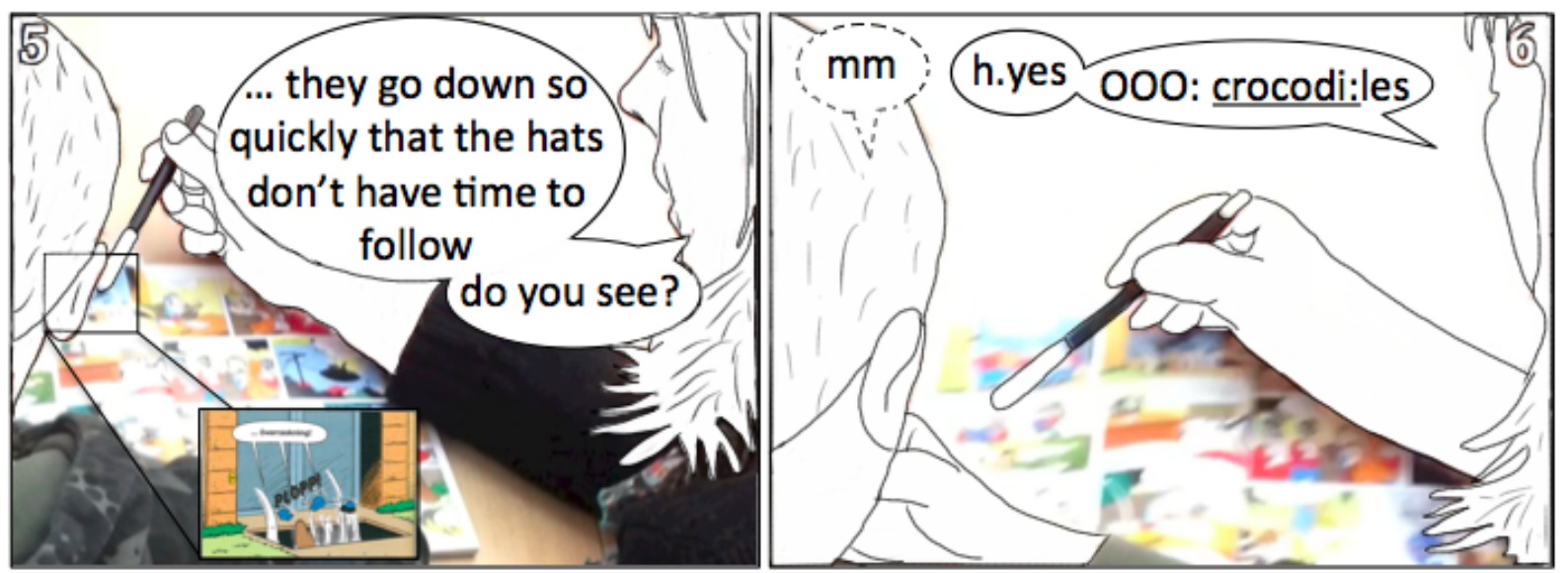

Figure 13. Excerpt 4, 7-9 


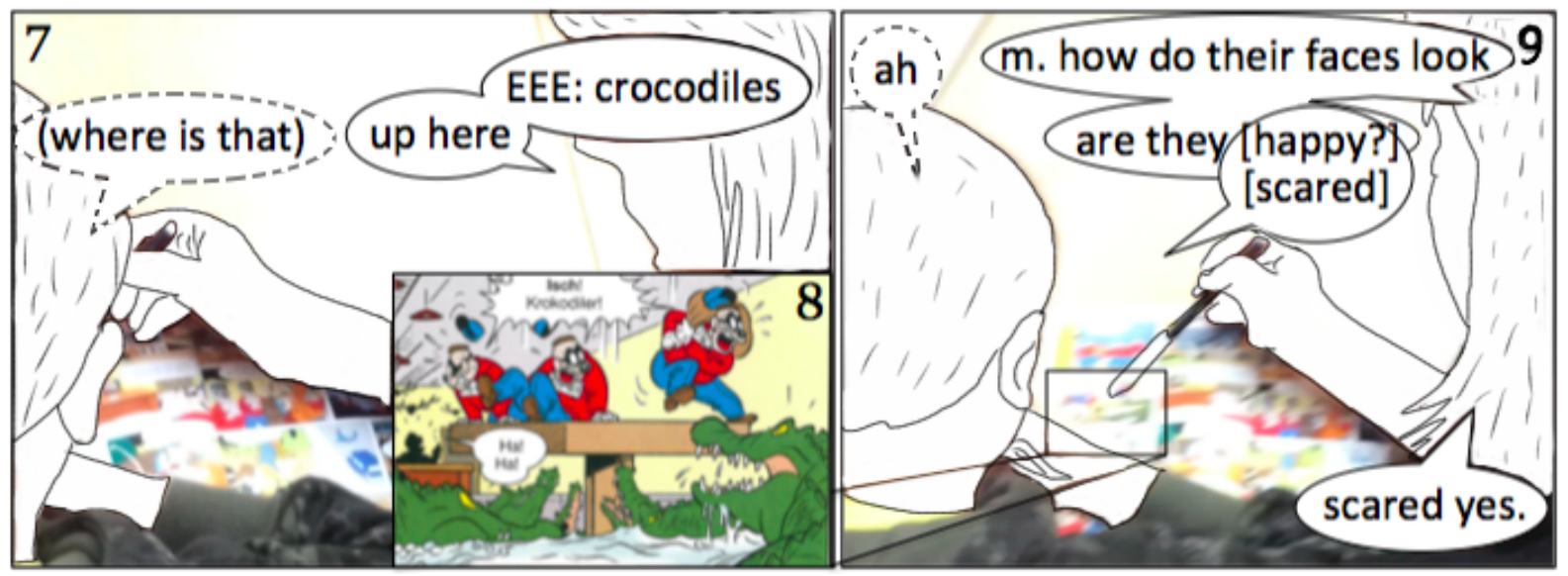

Here, the teacher, Anna (on the right), is reading the text aloud in the speech bubbles panelby-panel (see Appendix 2), pointing to the text and some of the imagery. She points to the third panel on the page (2) and says, in a high-pitched voice, "OOO: crocodi:les" (1), vocally mimicking the fear in the Beagle Boys' faces. However, the pupil, John (on the left), shows that he is still focusing on the previous panel (3), as he, in overlap, reads the sound text, "Plopp!", and points to text in the panel (4). Anna makes a brief affirmation of his observation, by repeating this word and pointing out the three hats (4-5). So John seemingly orients to text outside the speech bubbles, whereas Anna tends to focus her reading on the bubbles themselves. The larger font and bold face of the sound effect in combination with the visual elements (hats in the air, visual motion streaks) could possibly act as a visual attractant for John (cf. Eisner 1985/2008).

In her article on booktalk dilemmas, Eriksson Barajas argues that comprehension of all parts is important for pupils' understanding of a literary text (e.g. the total collection of words make up a unit) $(2002,14)$. In the present excerpt, Anna's third consecutive interpretation of the same bubble (7) changes the initially expressed vowel sound (compared to 1 and 6) form "OOO:" to "EEE:". An astute observer will note that the actual written text in the bubble (2) is, in fact, not a prolonged singular vowel sound as Anna expresses it, but rather the word "Isch!” (an English equivalent could be "Yuck!”), possibly expressing disgust. Anna asks John about the emotional state of the Beagle Boys by drawing visual attention to how "their faces look" (9). The expression on the Beagle Boys' faces - widened eyes and open mouths together with their hair standing on end and their hats jumping into the air - are all signs interpreted by Anna as expressions of fear, rather than disgust. John seemingly makes a similar interpretation (or is at least shown to present an acceptable answer), as he overlaps with her and says "scared" (10). Unlike the other excerpts, in which the bubbles have been discussed separately from any specific character imagery, this reading also shows an orientation to the character's faces. In Excerpt 3 Anna had to perform an embodied 
illustration of the root of the sound, whereas in this excerpt the characters are available to both readers, so throughout the reading Anna can refer to them while explaining the prosody both verbally and by pointing. Continuing Eriksson Barajas' (2002) argument, this excerpt shows Anna combining visual and textual features, emphasizing a connection between the text, the bubble shape, and the facial expressions of the characters, demonstrating a pedagogical orientation to this combination of modes as layers of literacy relevant to the pupil as a reader and composer of comics (cf. Heath and Bhagat 2005).

\section{Discussion}

This article has investigated how teachers and pupils in classroom interaction construct comic book speech and thought bubbles as devices of literary interaction.

Even though pupils have a familiarity with comics, as well as speech and thought bubbles (Yannicopoulou 2004), bubbles can differ between comic styles and genres, depending on cultural influences and time period. Therefore, it was of interest to investigate classroom work with comics to see whether teachers assume knowledge of bubbles and treat it as common sense, or, as it turned out, whether this is an aspect of comics that merits instruction.

With the first excerpt, it was demonstrated that the teacher prompts a construction of common knowledge of bubbles - performing the action of establishing the topic of a lesson. Even though this is a literary device most pupils have presumably seen, and would have no problem recognizing and understanding when reading, not all pupils are familiar with comics. Thus, teacher Anna constructs the lesson, and bubbles, as requiring mutual understanding within the context of the classroom. However, she does this by producing the pupils as the bearers of knowledge through social actions, demonstrated above.

With regard to the differences between individual bubbles, the participants construct literary functions for the different visual means of bubbles, e.g. identifying speaker (root) through the use of lines (tails), and using different bubble shapes to separate inner thought and outer dialogue, and identifying narrative focalization. In her article, Comer (2015) demonstrates how focalization becomes an important aspect of students' graphic narrative design. Not only does it allow the reader access to thoughts and emotions that the other characters of the story might not be privy to; Comer's students also use focalization to shift the perspective of time between the present and the past. Comer demonstrates the use of focalization in visual narratives as a means for students to effectively tell the story they want to tell. In the present article, the pupils and the teacher construct ways of differentiating between internal focalization (thought bubbles giving the reader access to a character's inner 
thoughts) and external focalization (whereby speech bubbles restrict the reader to only the public monologue or dialogue, in much the same way as the bubbles are perceived by the other characters in the story). Cohn (2013a) argues that the use of thought bubbles as a narrative perspective has become less popular in modern comics, and that instead the use of narrative captions has increased. Regardless of this, both methods (bubbles and captions) provide "the same window into characters' thoughts, just in a different surface representation" (Cohn 2013a, 40). In the present article, the pupils do show an awareness of thought bubbles as a means of displaying focalization, as evinced by Josefin in Excerpt 3.

In this way, utilizing the construction of comic book bubbles as a way of learning about narrative focalization could be an important tool for developing children's storytelling and understanding of narrative structure - both of which are important aspects of their literacy development. Teachers cannot assume that all pupils have knowledge of comics and their narrative styles (including how bubbles work), and the participants here demonstrate some of the advantages of working with bubbles. As bubbles are but a part of the many different visual means of narrative in comics, it is of interest to further investigate how they are utilized in classroom instruction.

The present article also investigates how participants draw upon comic book bubbles' visual mode of displaying talk, when constructing bubbles as literary devices. A combination of multimodal aspects of participant interaction - such as gestures, visual materials, and talk is frequently drawn upon in this setting to construct the aural and sensational qualities of different bubbles, i.e. the prosody of sound effects and characters' verbal interaction. As such, in interactions where there is no comic book character, the teacher takes on the role of the imagined character expressing a particular bubble, providing a means of displaying emotion and sensation - how the messages sound and feel to the reader. This manner of providing prosody to textual messages may help pupils develop their aesthetic narratives, and is a sophisticated way of combining words and pictures, even when one of these aspects is lacking.

By investigating how the social actions of teachers and pupils construct speech and thought bubbles in interaction around comics literacy, the present article sheds light on 1) how participants negotiate common knowledge in making bubbles publicly accessible as devices for comics literacy, 2) how they utilize combinations of interactional modalities to make sense of bubbles' content, and 3) how they suggest and negotiate the meaning of visual aspects such as bubble shape, font style, and punctuation to enable the literary function of the bubbles to display prosody and sensation. As a possible didactic tool for developing 
children's literacy, this demonstrates that comics as a format provide teachers and pupils with the means of engaging aspects of literacy to talk about what speech and thought bubbles do create sound and feeling out of ink and paper.

\section{Notes}

${ }^{1}$ Henceforth, the term comics is used for all manner of comic books, comic strips and graphic novels.

${ }^{2}$ As the present article does not directly take part in this debate, these are only a few examples of the literature that does. For those who are interested, I recommend Gene Yang's website and History of Comics in Education as a starting point: http://www.humblecomics.com/comicsedu/history.html.

3 The original language of the classroom is Swedish, and all transcripts have been translated by the author and proofread by a professional translator. The English translation has been kept as close as possible to the original language, representing the ungrammatical nature of spoken language.

${ }^{4}$ For a review of verbal/visual transcriptions, see Laurier (2014); for other examples of graphic transcripts, see Haddington and Rauniomaa (2014), Ivarsson (2010), Lindwall, Lindström, and Bernhard (2002), and Lindwall and Ivarsson (2010).

${ }^{5}$ Donald Duck panels in the excerpt are (C) DISNEY, and are used with permission.

\section{References}

Allington, Daniel. 2012. "Private experience, textual analysis, and institutional authority: The discursive practice of critical interpretation and its enactment in literary training." Language and Literature 21 (2):211-225.

Allington, Daniel, and Joan Swann. 2009. "Researching literary reading as social practice." Language and Literature 18 (3):219-230.

Author. (submitted). "XXXXXXXXXX."

Barks, Carl. 2013/1952. "Jul i Pengalösa." Kalle Anka och hans vänner, 68-99.

Barnes, Douglas. 1976. From Communication to Curriculum. Harmondsworth, UK: Penguin Books.

Bitz, Michael. 2004. "The Comic Book Project: Forging Alternative Pathways to Literacy." Journal of Adolescent \& Adult Literacy 47 (7):574-586.

Bitz, Michael. 2008. "The Comic Book Project." SchoolArts: The Art Education Magazine for Teachers 108 (4):23-25.

Bruner, Jerome, S. 1990. Acts of Meaning. Cambridge, MA \& London, UK: Harvard University Press.

Bucher, Katherine T., and Lee M. Manning. 2004. "Bringing Graphic Novels into a School's Curriculum." Clearing House 78 (2):67.

Chute, Hillary. 2008. "Comics as Literature? Reading Graphic Narrative." PMLA 123 (2):452-465. 
Cohn, Neil. 2007. "A Visual Lexicon." The Public Journal of Semiotics 1 (1):35-56.

Cohn, Neil. 2012. "Comics, Linguistics, and Visual Language: The past and future of a field." In Linguistics and the Study of Comics, edited by Frank Bramlett, 92-118. New York: Palgrave MacMillan.

Cohn, Neil. 2013a. "Beyond speech balloons and thought bubbles: The integration of text and image." Semiotica 197:35-63.

Cohn, Neil, ed. 2013b. The visual language of comics: Introduction to the structure and cognition of sequential images. London, UK: Bloomsbury.

Comer, Kathryn. 2015. "Illustrating Praxis: Comic Composition, Narrative Rhetoric, and Critical Multiliteracies." Composition Studies 43 (1):75-104.

Culler, Jonathan. 1997. Literary Theory: A Very Short Introduction. Oxford: Oxford University Press.

Dickinson, Hannah, and Maggie Werner, M. 2015. "Beyond Talking Heads: Sourced Comics and the Affordances of Multimodality." Composition Studies 43 (1):51-74.

Du Bois, John W. 2007. "The stance triangle." In Stancetaking in Discourse: Subjectivity, evaluation, interaction, edited by Robert Englebretson. Amsterdam/Philadelphia: John Benjamins Publishing Company.

Edwards, A. D., and V. J. Furlong. 1978. The Language of Teaching. London, UK: Heinemann.

Edwards, Derek, and Neil Mercer. 1987. Common knowledge: the development of understanding in the classroom. London and New York: Methuen.

Eisner, Will. 1985/2008. Comics and sequential art: principles and practices from the legendary cartoonist / Will Eisner. Rev. ed. of: Comics \& sequential art. 1985 ed. New York, NY: W. W. Norton \& Company. Original edition, 1985. Reprint, 2008.

Eriksson Barajas, Katarina. 2002. "Booktalk Dilemmas: teachers' organisation of pupils' reading." Scandinavian Journal of Educational Research 46 (4):391-408.

Garfinkel, Harold. 1967/1984. Studies in Ethnomethodology. Cambridge, UK: Polity Press. Original edition, 1967. Reprint, 1984.

Genette, Gérard. 1983. Narrative Discourse: An Essay in Method. Ithaca, NY: Cornell UP.

Gillenwater, Cary. 2014. "Reading Images: The Phenomenon of Intertextuality and How It May Contribute to Developing Visual Literacy with Advanced Placement English/Language Arts Students." Journal of Ethnographic \& Qualitative Research 8:251-263. 
Goodwin, Charles, and Marjorie Harness Goodwin. 2000. "Emotion within Situated Activity." In Linguistic Anthropology: A Reader., edited by A. Duranti, 239-257. Malden, MA: Blackwell. Original edition, pp. 33-54 in Communication: An Arena of Development, edited by Nancy Budwig, Ina C Uzgris and James V. Wertsch, Stamford CT: Ablex 2000.

Goodwin, Marjorie Harness, Asta Cekaite, and Charles Goodwin. 2012. "Emotion as Stance." In Emotion in Interaction, edited by Marja-Leena Sorjonen and Anssi Perakyla, 16-41. Oxford: Oxford University Press.

Haddington, Pentti, and Mirka Rauniomaa. 2014. "Interaction Between Road Users: Offering Space in Traffic." Space and Culture 17 (2):176-190.

Hammond, Heidi Kay. 2009. "Graphic Novels and Multimodal Literacy: A Reader Response Study." PhD, Graduate School of the University of Minnesota.

Heath, Shirley Brice, and Vikram Bhagat. 2005. "Reading Comics, the Invisible Art." In Handbook of Research on Teaching Literacy Through the Commuicative and Visual Arts, edited by James Flood, Shirley Brice Heath and Diane Lapp, 586-591. New York: Lawrence Erlbaum Associates.

Ivarsson, Jonas. 2010. "Developing the construction sight: Architectural education and technological change." Visual Communication 9 (2):171-191.

Jacobs, Dale. 2007. "Marveling at "The Man Called Nova": Comics as Sponsors of Multimodal Literacy." College Composition and Communication 59 (2):180-205.

Jacobs, Dale. 2013. Graphic Encounters: Comics and the Sponsorship of Multimodal Literacy. New York: Bloomsbury Academic.

Jaffe, Alexandra, ed. 2009. Stance: Sociolinguistic Perspectives, Oxford studies in sociolinguistics. New York: Oxford University Press.

Jefferson, Gail. 2004. "Glossary of transcript symbols with an introduction." In Conversation Analysis: Studies from the first generation, edited by Gene H. Lerner, 13-31. Amsterdam/Philadelphia: John Benjamins.

Jonker, Frank, and Paul Hoogma. 2005/2013. "Den föränderliga Fläcken." Välkommen till Ankeborg, 6-16.

Kress, Günther. 2010. Multimodality: A social semiotic approach to contemporary communication London \& New York: Routledge.

Lannon, Keegan. 2013. "Visualizing Words: The Function of Words in Comics." International Journal of Comic Art 15 (1):287-305. 
Laurier, Eric. 2014. "The Graphic Transcript: Poaching Comic Book Grammar for Inscribing the Visual, Spatial and Temporal Aspects of Action." Geography Compass 8 (4):235248.

Lindwall, Oskar, and Jonas Ivarsson. 2010. "Differences that make a difference: Contrasting the local enactment of two technologies in a kinematics lab." In Learning across sites: New tools, infrastructures and practices., edited by Sten Ludvigsen, Andreas Lund, Ingvill Rasmussen and Roger Säljö, 364-380. London: Routledge.

Lindwall, Oskar, Berner Lindström, and Jonte Bernhard. 2002. "Organizing Time and Space: Technology, Task Structure, and Embodied Inquiry in a Kinematics Lab." In Utm@ningar \& e-frestelser: IT och skolans lärkultur., edited by Roger Säljö and Jonas Linderoth, 119-144. Stockholm: Prisma.

Low, David. 2012. ""Spaces Invested with Content": Crossing the "Gaps" in Comics with Readers in Schools." Children's Literature in Education 43 (4):368-385.

McCloud, S. 1994. Understanding Comics: The Invisible Art: William Morrow Paperbacks.

Mehan, Hugh. 1979. Learning Lessons - Social Organization in the Classroom. Cambridge, MA \& London, UK: Harvard University Press.

Pantaleo, Sylvia. 2011. "Grade 7 Students Reading Graphic Novels: 'You Need To Do a Lot of Thinking'." English in Education 45 (2):113-131.

Pantaleo, Sylvia. 2012. "Exploring Grade 7 Students' Responses to Shaun Tan's "The Red Tree"." Children's Literature in Education 43 (1):51-71.

Pantaleo, Sylvia. 2013. "Paneling "Matters" in Elementary Students' Graphic Narratives." Literacy Research and Instruction 52 (2):150-171.

Potter, Jonathan. 1996. Representing Reality - Discourse, Rhetoric and Social Construction. London/Thousand Oaks/New Dehli: Sage. Reprint, 6th ed., 2005.

Potter, Jonathan. 2000. "Post-cognitive Psychology." Theory \& Psychology 10 (1):31-37.

Potter, Jonathan. 2003. "Discourse analysis and discursive psychology." In Qualitative research in psychology: Expanding perspectives in methodology and design, edited by P. M. Camic, J. E. Rhodes and L. Yardley, 73-94. Washington: American Psychological Association.

Potter, Jonathan. 2010. "Discursive psychology and the study of naturally occurring talk." In Qualitative Analysis: Issues of theory and method, edited by David Silverman, 187207. London: Sage.

Potter, Jonathan, and Derek Edwards. 1999. "Social Representations and Discursive Psychology: From Cognition to Action." Culture and Psychology 5 (4):447-458. 
Potter, Jonathan, and Derek Edwards. 2003. "Rethinking Cognition: On Coulter on Discourse and Mind." Human Studies 26:165-181.

Ripley, Dore. 2012. "Classroom Comics: Children's Medium and the New Literacy." Interdisciplinary Humanities 29 (1):99-113.

Sacks, Harvey, Emanuel A. Schegloff, and Gail Jefferson. 1974. "A simplest systematics for the organization of turn-taking for conversation." Language 50 (4):696-735.

Solstrand, Olaf, and Arild Midthun. 2013/2007. "Trolldom möter lärdom." Kalle Anka och hans vänner, 23-34.

Stivers, Tanya, and Jack Sidnell. 2005. "Introduction: Multimodal interaction." Semiotica $156(1 / 4): 1-20$.

Strömberg, Fredrik. 2016. "Comics studies in the Nordic countries - field or discipline?" Journal of Graphic Novels and Comics 7 (2):134-155.

Sutliff Sanders, Joe. 2016. "How Comics Became Kids' Stuff." In Good Grief! Children and Comics, edited by Michelle Ann Abate and Joe Sutliff Sanders, 9-28. Columbus, OH: Billy Ireland Cartoon Library \& Museum.

Swedish National Agency for Education. 2011. Curriculum for the compulsory school, preschool class and the recreation centre. edited by Swedish National Agency for Education. Stockholm: Swedish National Agency for Education.

The New London Group. 1996. "A Pedagogy of Multiliteracies: Designing Social Futures." Harvard Educational Review 66 (1):60-92.

Thompson, Terry. 2008. Adventures in Graphica. Portland, ME: Stenhouse Publishers.

Tilley, Carol L. 2012. "Seducing the Innocent: Fredric Wertham and the Falsifications That Helped Condemn Comics." Information \& Culture 47 (4):383-413.

Wertham, Fredric. 1954. Seduction of the Innocent. New York: Rinehart \& Company.

Wiggins, Sally, and Jonathan Potter. 2007. "Discursive psychology." In The SAGE handbook of qualitative research in psychology, edited by Carla Willig and Wendy StaintonRogers, 73-90. Los Angeles, CA: Sage.

Yannicopoulou, Angela. 2004. "Visual Aspects of Written Texts: Preschoolers View Comics." L1 - Educational Studies in Language and Literature 4:169-181. 
Appendix 1: Transcription key (inspired by Thompson 2008, 106, and Jefferson 2004)

\begin{tabular}{|c|c|c|}
\hline Description & Visual appearance & Reader guidance \\
\hline Round bubble & & Talk in normal tone \\
\hline $\begin{array}{l}\text { Connected bubbles } \\
\text { (with or without tail) }\end{array}$ & & Short pause between talk in bubbles \\
\hline Overlapping bubbles & & $\begin{array}{l}\text { Overlapping talk (first speaker has left } \\
\text { bubble, second speaker has right bubble, } \\
\text { upper lines of text connect to first speaker, } \\
\text { lower lines connect to second speaker) }\end{array}$ \\
\hline Jagged speech bubble & & Shouting/loud talk (turn) \\
\hline Broken speech bubble & & Quiet talk \\
\hline Underlined text & $\underline{\text { Talk }}$ & Verbal emphasis \\
\hline Capitals & TALK & Loud talk (part of turn) \\
\hline Parentheses & (talk) & $\begin{array}{l}\text { Muffled speech, author's best estimate as } \\
\text { to what is said }\end{array}$ \\
\hline Ellipses & $\ldots$ & $\begin{array}{l}\text { Short pause between panels (same speaker } \\
\text { continues) }\end{array}$ \\
\hline Dash & tal- & Cut off talk \\
\hline Question mark & talk? & Rising intonation \\
\hline Comma & talk, & Continued intonation \\
\hline Full stop & talk. & Falling intonation \\
\hline Colon & ta: $1 \mathrm{k}$ & Stretched-out vowel sound \\
\hline $\mathrm{H}$ followed by full stop & h. & Outbreath \\
\hline Apostrophe & talk'n/an'talk & Lost vowel sound/Contracted words \\
\hline
\end{tabular}


Appendix 2: Excerpt 4 comic (half-page, cut for space) (Jonker and Hoogma 2005/2013, 10, translated by Diös, Stefan) (C) Disney, used with permission.
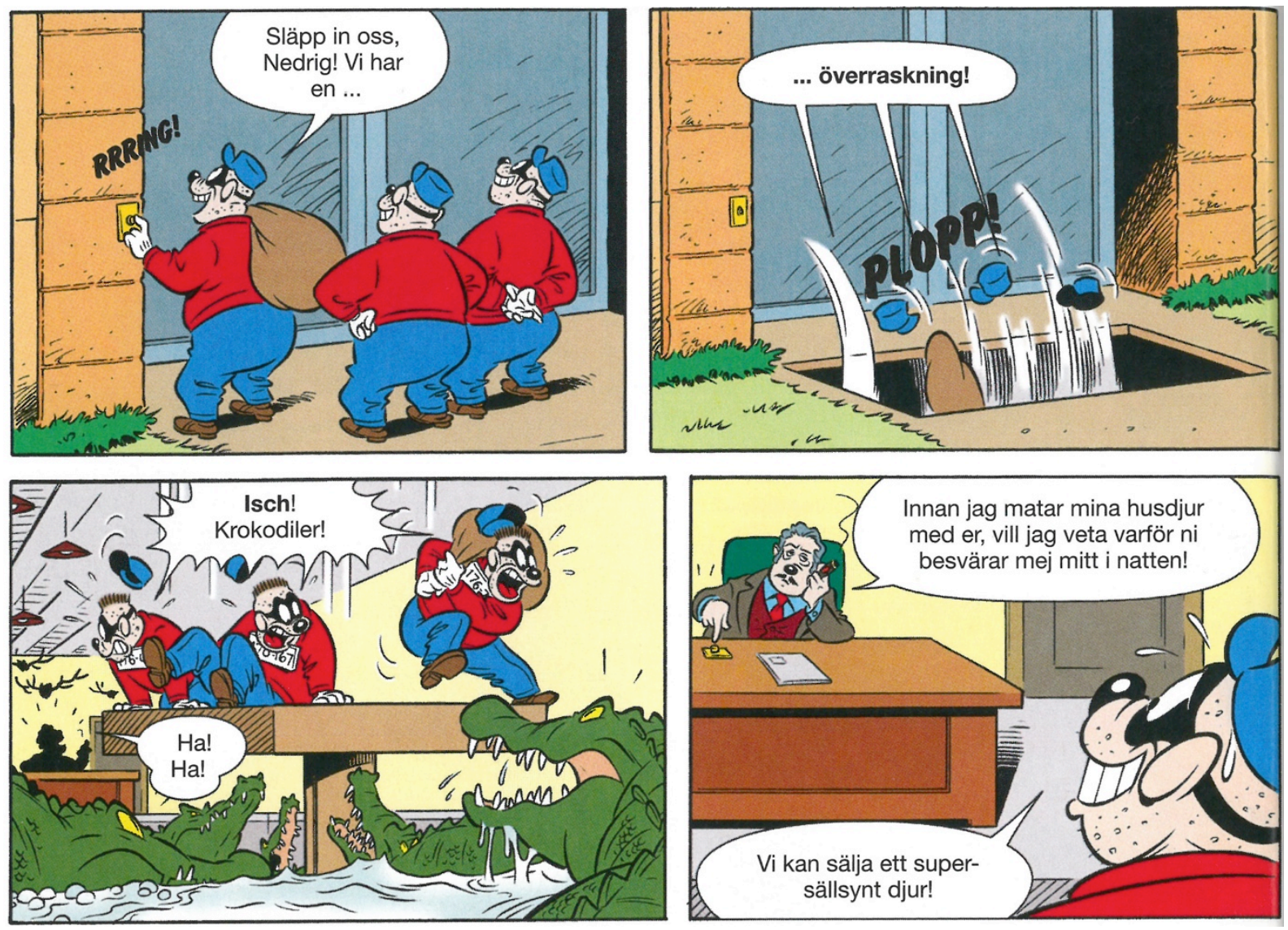